\title{
Effect of Particle Addition on Ultrasonic Degradation Reaction Rate
}

\author{
Daisuke Kobayashi1,2*, Kaho Shimakage², Chiemi Honma², Hideyuki Matsumoto³, \\ Katsuto Otake ${ }^{2}$, Atsushi Shono \\ ${ }^{1}$ Department of Green and Sustainable Chemistry, Tokyo Denki University, Tokyo, Japan \\ ${ }^{2}$ Department of Industrial Chemistry, Faculty of Engineering, Tokyo University of Science, Tokyo, Japan \\ ${ }^{3}$ Renewable Energy Research Center, Department of Energy and Environment, Advanced Industrial Science and \\ Technology, Fukushima, Japan \\ Email: ${ }^{*}$ kobayashi@mail.dendai.ac.jp
}

Received 23 July 2015; accepted 28 August 2015; published 1 September 2015

Copyright (C) 2015 by authors and Scientific Research Publishing Inc.

This work is licensed under the Creative Commons Attribution International License (CC BY).

http://creativecommons.org/licenses/by/4.0/

c) (i) Open Access

\section{Abstract}

The ultrasonic degradation of methylene blue at a frequency of $490 \mathrm{kHz}$ was carried out in the absence and presence of $\mathrm{TiO}_{2}$ or $\mathrm{Al}_{2} \mathrm{O}_{3}$ particle, and the effects of amounts of particle on the enhancement of degradation rate constant estimated by assuming first-order-kinetics were investigated. The degradation reaction was enhanced by particle addition, and the apparent degradation rate constant is proportional to the increase in amount of particle. In addition, the constant of proportionality is not influenced by degraded material and ultrasonic frequency. However, particle type influences the constant of proportionality, and the value of $\mathrm{TiO}_{2}$ particle is about 6 times as large as that of $\mathrm{Al}_{2} \mathrm{O}_{3}$ particle.

\section{Keywords}

Degradation, Methylene Blue, Frequency, Particle Addition

\section{Introduction}

Ultrasound has been found to be an attractive advanced oxidation technology for the degradation of hazardous organic compounds in water [1]-[6]. Especially, degradation of phenol and some of its derivatives such as chlorophenol and nitrophenol using ultrasound has been investigated by many researchers [7]-[11]. The ultrasonic degradation of dyes has also been investigated [12]-[18]. In these studies, the effects of ultrasonic frequency, power, dissolved gas and solution $\mathrm{pH}$ on degradation have been investigated. In addition, the sonochemical

\footnotetext{
${ }^{*}$ Corresponding author.
}

How to cite this paper: Kobayashi, D., Shimakage, K., Honma, C., Matsumoto, H., Otake, K. and Shono, A. (2015) Effect of Particle Addition on Ultrasonic Degradation Reaction Rate. Open Journal of Acoustics, 5, 67-72.

http://dx.doi.org/10.4236/oja.2015.53006 
reaction is enhanced by particle addition. Especially, the combination of photocatalysis and ultrasound is considered to enhance the degradation rate [4] [5]. The degradation of phenol by ultrasonic irradiation in the presence of $\mathrm{TiO}_{2}$ particles has been investigated in complete darkness [19]. Sekiguchi and Saita have investigated the effect of $\mathrm{Al}_{2} \mathrm{O}_{3}$ particles on the degradation of chlorobenzene in an ultrasonic field [20].

In our previous study, the ultrasonic degradation of methylene blue in the absence and presence of $\mathrm{TiO} 2$ or $\mathrm{Al}_{2} \mathrm{O}_{3}$ particles for various frequencies was carried out [21]. The enhancement of degradation rate by particle addition was influenced by both ultrasonic frequency and type or diameter of particles. However, the effects of degraded materials on enhancement of reaction rate were not investigated quantitatively.

In this study, the ultrasonic degradation of methylene blue was carried out, and the effects of ultrasonic irradiation condition on the degradation rate constant were investigated. The effects of degraded materials and particle type on enhancement of degradation were also investigated by comparing previous study.

\section{Experimental Methods}

Figure 1 shows the experimental apparatus. A stainless steel vibration plate attached with PZT transducer (Honda Electronics Co., Ltd.) was installed in the center of the water bath at the bottom. The ultrasonic frequency was operated at $490 \mathrm{kHz}$. The diameters of the vibration plate, and the $490 \mathrm{kHz}$ transducer were $100 \mathrm{~mm}$, $50 \mathrm{~mm}$, and $50 \mathrm{~mm}$, respectively. The transducers were driven by a power amplifier (1040L, E\&I), which in turn was driven by a continuous sinusoidal wave produced using a signal generator (WF1974, NF Corp.). The effective electric power input to the transducer was calculated from the voltage at both ends of the transducer, the current measured using an oscilloscope (TDS3012C, Tektronix Inc.), and a current probe (TCP202, Tektronix Inc.). The diameter and the approximate volume of the glass reactor were $85 \mathrm{~mm}$ and $1 \mathrm{~L}$, respectively. The temperature of the water bath was kept constant at $298 \mathrm{~K}$ by a thermostat. In addition, the temperature of sample solution in the reactor was between $298 \mathrm{~K}$ and $303 \mathrm{~K}$.

Table 1 shows the experimental conditions for methylene blue degradation. Process variables were defined as follows: irradiation time and amount of particles $\left(\mathrm{TiO}_{2}\right.$ or $\left.\mathrm{Al}_{2} \mathrm{O}_{3}\right)$ addition $(w)$. The ultrasonic frequency $(f)$, ultrasonic output power $(P)$, distance between the ultrasonic transducer and the bottom of the reactor $\left(L_{1}\right)$, distance between the ultrasonic transducer and the level of the water bath $\left(L_{2}\right)$, volume of the sample solution $(V)$, temperature of the water bath $(T)$, and initial methylene blue concentration $\left(C_{0}\right)$ were kept constant. The diameters of additive particles of $\mathrm{TiO}_{2}$ and $\mathrm{Al}_{2} \mathrm{O}_{3}$ using this study were $300 \mathrm{~nm}$ and $50 \mu \mathrm{m}$, respectively.

Before ultrasonic irradiation, the sample solution and the remaining space in the reactor were deoxygenated with a nitrogen gas flow for $20 \mathrm{~min}$. After deoxygenation, the sample was irradiated with ultrasound under a continuous flow of nitrogen gas $(0.1 \mathrm{~L} / \mathrm{min})$. After ultrasonic irradiation, the methylene blue concentration $(C)$

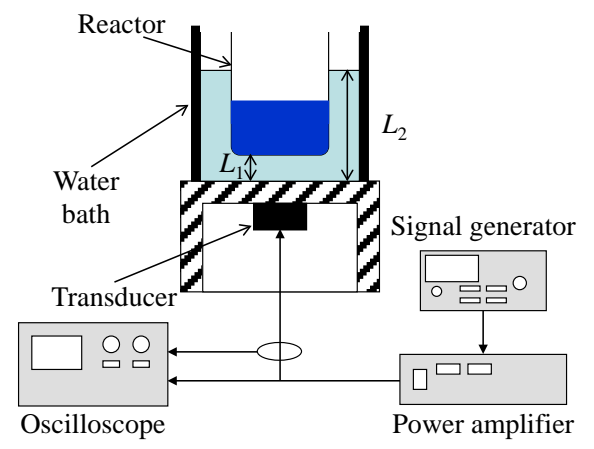

Figure 1. Experimental apparatus.

Table 1. Experimental conditions.

\begin{tabular}{|c|c|c|c|c|c|c|c|c|}
\hline$\underset{[\mathrm{kHz}]}{f}$ & $\begin{array}{c}P \\
{[\mathrm{~W}]}\end{array}$ & $\begin{array}{c}L_{1} \\
{[\mathrm{~mm}]}\end{array}$ & $\begin{array}{c}L_{2} \\
{[\mathrm{~mm}]}\end{array}$ & $\begin{array}{c}T \\
{[\mathrm{~K}]}\end{array}$ & $\begin{array}{c}C_{0} \\
{[\mathrm{mM}]}\end{array}$ & $\begin{array}{c}t \\
{[\mathrm{~min}]}\end{array}$ & $\begin{array}{c}V \\
{[\mathrm{~mL}]}\end{array}$ & $\begin{array}{c}w \\
{[\mathrm{~g}]}\end{array}$ \\
\hline 490 & 8 & 10 & 60 & 298 & 0.0105 & $0-30$ & 100 & $0-2$ \\
\hline
\end{tabular}


was determined by measuring the absorbance of the sample at a wavelength of $665 \mathrm{~nm}$ using UV-vis spectrometer (Agilent 8453, Agilent Technologies). The determined absorbance was converted to a concentration through the standard curve of methylene blue. Before the analysis, the suspension was centrifuged to remove particles. The ultrasonic power in the reactor was measured by calorimetry [22].

\section{Results and Discussion}

\subsection{Degradation of Methylene Blue}

Figure 2 shows the effects of amount of $\mathrm{TiO}_{2}$ particle addition on the time dependence of methylene blue concentration at a frequency of $490 \mathrm{kHz}$ and an ultrasonic power of $8 \mathrm{~W}$. The methylene blue degradation is enhanced by $\mathrm{TiO}_{2}$ particle addition, and the degradation rate increases with increasing $\mathrm{TiO}_{2}$ particles amount. It is also found that the degradation of methylene blue in the presence of particles was also a pseudo-first-order reaction. Figure 3 shows the effects of amount of $\mathrm{TiO}_{2}$ or $\mathrm{Al}_{2} \mathrm{O}_{3}$ particles addition on the enhancement of degradation of methylene blue at a frequency of $490 \mathrm{kHz}$ and an ultrasonic power of $8 \mathrm{~W}$. Here, $k_{\text {app }}$ and $k_{\text {app, } 0}$ represents the apparent degradation rate constant and the apparent degradation rate constant in the absence of particles, respectively. The apparent degradation rate constant is proportional to the increase in amount of $\mathrm{TiO}_{2}$ particle until amounts of particle is approximately $1.3 \mathrm{~g}$. The optimal concentration of $\mathrm{TiO}_{2}$ was $0.25 \mathrm{~g} / \mathrm{L}$ in the photocatalytic irradiation system, because the UV light was hindered by the excess $\mathrm{TiO}_{2}$ particles [23]. However, such a phenomenon is not observed in this ultrasonic irradiation system. Thus, $\mathrm{TiO}_{2}$ particles are used effectively in the sonocatalytic irradiation system.

On the other hand, ultrasonic degradation of methylene blue was also improved in the presence of $\mathrm{Al}_{2} \mathrm{O}_{3}$ particles, and the apparent rate constant is also proportional to the increase in amount of $\mathrm{Al}_{2} \mathrm{O}_{3}$ particle. Moreover, the enhancement of degradation rate constant by $\mathrm{TiO}_{2}$ particle addition is more effective than that by $\mathrm{Al}_{2} \mathrm{O}_{3}$ particle addition. It is guessed that the presence of the reactive particles of $\mathrm{TiO}_{2}$ enhances $\mathrm{OH}$ radical generation.

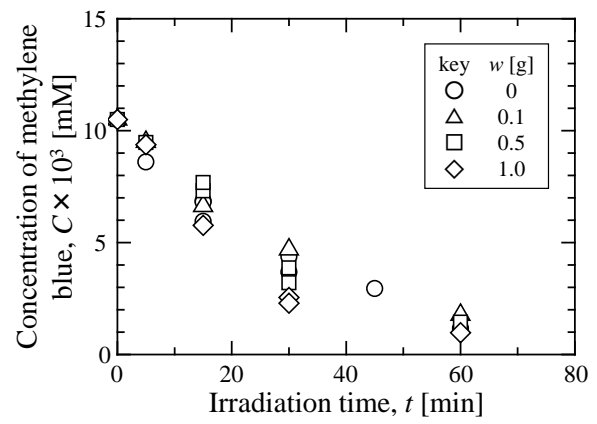

Figure 2. Effects of amount of $\mathrm{TiO}_{2}$ particle addition on the time dependence of methylene blue concentration at a frequency of $490 \mathrm{kHz}$ and an ultrasonic power of $8 \mathrm{~W}$.

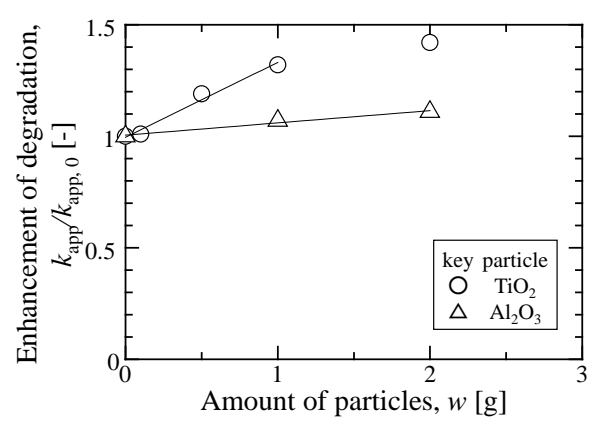

Figure 3. Effects of amount of $\mathrm{TiO}_{2}$ or $\mathrm{Al}_{2} \mathrm{O}_{3}$ particles addition on the enhancement of degradation of methylene blue at a frequency of $490 \mathrm{kHz}$ and an ultrasonic power of $8 \mathrm{~W}$. 


\subsection{Degradation of Chlorobenzene and Phenol}

Sekiguchi and Saita have been investigated the effects of $\mathrm{Al}_{2} \mathrm{O}_{3}$ particle addition on degradation of chlorobenzene [20]. The reaction rate of chlorobenzene was enhanced by $\mathrm{Al}_{2} \mathrm{O}_{3}$ particle addition and degradation was a pseudo-first-order reaction. Figure 4 shows the effect of amount of $\mathrm{Al}_{2} \mathrm{O}_{3}$ particle addition on the apparent degradation rate constant of chlorobenzene. Here, ultrasonic frequency, ultrasonic power, initial concentration of chlorobenzene, volume of sample solution, and $\mathrm{Al}_{2} \mathrm{O}_{3}$ particle diameter were $20 \mathrm{kHz}, 300 \mathrm{~W}, 4.3 \mathrm{mM}, 35 \mathrm{~mL}$, and $2 \mathrm{~mm}$, respectively. The apparent degradation rate constant is proportional to the increase in amount of $\mathrm{Al}_{2} \mathrm{O}_{3}$ particle.

\subsection{Effect of Particle Addition on Apparent Degradation Rate Constant}

Kubo et al. have been investigated the effects of $\mathrm{TiO}_{2}$ particles addition on degradation of phenol [19]. The reaction rate of phenol was enhanced by $\mathrm{TiO}_{2}$ particle addition and degradation was a pseudo-first-order reaction. Figure 5 shows the effect of amount of $\mathrm{TiO}_{2}$ particle addition on the apparent degradation rate constant of phenol. Here, ultrasonic frequency, ultrasonic power, initial concentration of phenol, volume of sample solution, and $\mathrm{TiO}_{2}$ particle diameter were $20 \mathrm{kHz}, 50 \mathrm{~W}, 1 \mathrm{mM}, 25 \mathrm{~mL}$, and $95 \mathrm{~nm}$, respectively. The apparent degradation rate constant is proportional to the increase in amount of $\mathrm{TiO}_{2}$ particle until amounts of particle is approximately $7 \mathrm{~g}$.

\subsection{Effect of Particle Addition on Enhancement of Degradation Reaction}

The degradation reactions of methylene blue in this study, chlorobenzene, and phenol were enhanced by particle addition, and the apparent degradation rate constant is proportional to the increase in amount of particle. Therefore, we simply expressed the apparent degradation rate constants in the presence of particles as the following

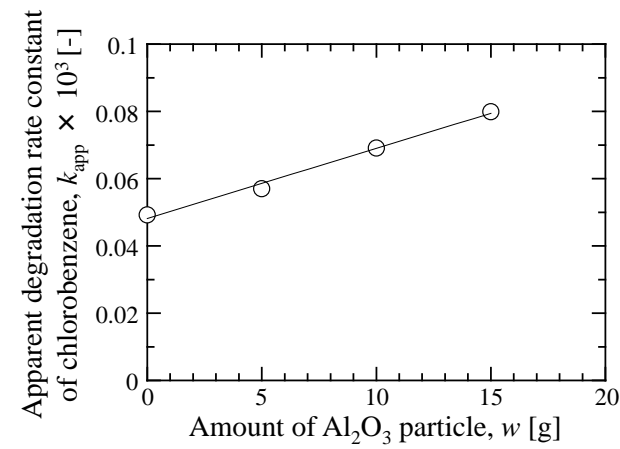

Figure 4. Effect of amount of $\mathrm{Al}_{2} \mathrm{O}_{3}$ particle addition on the apparent degradation rate constant of chlorobenzene at a frequency of $20 \mathrm{kHz}$ and an ultrasonic power of $300 \mathrm{~W}$.

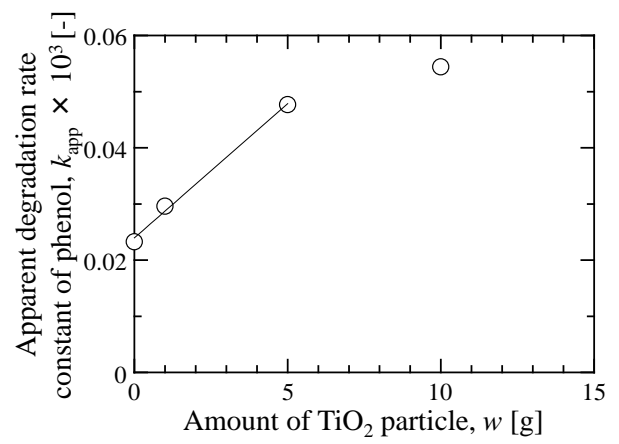

Figure 5. Effect of amount of $\mathrm{TiO}_{2}$ particle addition on the apparent degradation rate constant of phenol at a frequency of $20 \mathrm{kHz}$ and an ultrasonic power of $50 \mathrm{~W}$. 
Table 2. Effects of degradation conditions on degradation rate constants without particle addition and constant of proportionality (b).

\begin{tabular}{|c|c|c|c|c|c|c|c|}
\hline Degraded material & Particle & $\stackrel{f}{f}$ & $\begin{array}{c}P \\
{[\mathrm{~W}]}\end{array}$ & $\begin{array}{c}V \\
{[\mathrm{~mL}]}\end{array}$ & $\begin{array}{c}w \\
{[\mathrm{~g}]}\end{array}$ & $\begin{array}{c}k_{\mathrm{app}, 0} \\
{\left[\mathrm{~s}^{-1}\right]}\end{array}$ & $\begin{array}{c}b \\
{\left[g^{-1}\right]}\end{array}$ \\
\hline Methylene blue (Figure 3) & $\mathrm{TiO}_{2}$ & 490 & 8 & 100 & $0-2$ & 0.00045 & 0.33 \\
\hline Methylene blue (Figure 3) & $\mathrm{Al}_{2} \mathrm{O}_{3}$ & 490 & 8 & 100 & $0-2$ & 0.00045 & 0.058 \\
\hline Chlorobenzene (Figure 4) & $\mathrm{Al}_{2} \mathrm{O}_{3}$ & 20 & 300 & 35 & $0-15$ & 0.048 & 0.044 \\
\hline Phenol (Figure 5) & $\mathrm{TiO}_{2}$ & 20 & 50 & 25 & $0-10$ & 0.000024 & 0.20 \\
\hline
\end{tabular}

empirical relation Equation (1).

$$
k_{\text {app }}=k_{\text {app }, 0}+a w
$$

Here, $a$ represents constant of proportionality. In order to ignore the influence of degraded substance and ultrasonic frequency on degradation rate constant, Equation (2) is obtained by transforming Equation (1).

$$
\frac{k_{\text {app }}}{k_{\text {app }, 0}}=1+b w
$$

Here, $b$ represents constant of proportionality. Table 2 shows the effects of degradation conditions on deg- radation rate constants without particle addition and constant of proportionality $(b)$. The constant of proportionality are calculated from lines in Figures 3-5. It is found that the constant of proportionality is not influenced by degraded material and ultrasonic frequency. However, particle type influences the constant of proportionality, and the value of $\mathrm{TiO}_{2}$ particle is about 6 times as large as that of $\mathrm{Al}_{2} \mathrm{O}_{3}$ particle. On the other hand, the particle amount used for enhancement of reaction is considered to be influenced by ultrasonic frequency and ultrasonic power.

\section{Conclusion}

The ultrasonic degradation of methylene blue at a frequency of $490 \mathrm{kHz}$ was carried out in the absence and presence of $\mathrm{TiO}_{2}$ or $\mathrm{Al}_{2} \mathrm{O}_{3}$ particle. The degradation reaction was enhanced by particle addition, and the apparent degradation rate constant is proportional to the increase in amount of particle. In addition, the constant of proportionality is not influenced by degraded material and ultrasonic frequency. However, particle type influences the constant of proportionality.

\section{References}

[1] Adewuri, Y.G. (2001) Sonochemistry: Environmental Science and Engineering Applications. Industrial and Engineering Chemistry Research, 40, 4681-4175. http://dx.doi.org/10.1021/ie010096l

[2] Park, B., Shin, D., Cho, E. and Khim, J. (2012) Effect of Ultrasonic Frequency and Power Density for Degradation of Dichloroacetonitrile by Sonolytic Ozonation. Japanese Journal of Applied Physics, 51, Article ID: 07GD07. http://dx.doi.org/10.7567/JJAP.51.07GD07

[3] Xu, Z., Mochida, K., Naito, T. and Yasuda, K. (2012) Effects of Operational Conditions on 1,4-Dioxane Degradationby Combined Use of Ultrasound and Ozone Microbubbles. Japanese Journal of Applied Physics, 51, Article ID: 07GD08. http://dx.doi.org/10.1143/JJAP.51.07GD08

[4] Cho, E., Park, B., Na, S. and Khim, J. (2012) Effects of Power Density and $\mathrm{TiO}_{2}$ Dose in the Sonocatalytic Degradationof Diethyl Phthalate Using High Frequency. Japanese Journal of Applied Physics, 51, Article ID: 07GD09. http://dx.doi.org/10.1143/JJAP.51.07GD09

[5] Park, B., Cho, E., Park, H. and Khim, J. (2011) Sonophotocatalytic Destruction of Chloroform: Comparison of Processes and Synergistic Effects. Japanese Journal of Applied Physics, 50, Article ID: 07HE10.

[6] Naruke, Y. and Harada, H. (2011) Sonophotocatalytic Sonolysis of Short-Chain Organic Dicarboxylic Acid Solutions, Japanese Journal of Applied Physics, 50, 07HE15. http://dx.doi.org/10.1143/JJAP.50.07HE15

[7] Kobayashi, D., Sano, K., Takeuchi, Y. and Terasaka, K. (2011) Effect of Irradiation Distance on Degradation of Phenol Using Indirect Ultrasonic Irradiation Method. Ultrasonics Sonochemistry, 18, 1205-1210. 
http://dx.doi.org/10.1016/j.ultsonch.2011.01.010

[8] Kidak, R and Ince, N.H. (2006) Ultrasonic Destruction of Phenol and Substituted Phenols: A Review of Current Research. Ultrasonics Sonochemistry, 13, 195-199. http://dx.doi.org/10.1016/j.ultsonch.2005.11.004

[9] Pétrier, C. and Francony, A. (1997) Ultrasonic Waste-Water Treatment: Incidence of Ultrasonic Frequency on the Rate of Phenol and Carbon Tetrachloride Degradation. Ultrasonics Sonochemistry, 4, 295-300. http://dx.doi.org/10.1016/S1350-4177(97)00036-9

[10] Berlan, J., Trabelsi, F., Delmas, H., Wilhelm, A.M. and Petrignani, J.F. (1994) Oxidative Degradation of Phenol in Aqueous Media Using Ultrasound. Ultrasonics Sonochemistry, 1, S97-S102. http://dx.doi.org/10.1016/1350-4177(94)90005-1

[11] Serpone, N., Terzian, R., Colarusso, P., Minero, C., Pelizzetti, E. and Hidaka, H. (1993) Sonochemical Oxidation of Phenol and Three of Its Intermediate Products in Aqueous Media: Catechol, Hydroquinone, and Benzoquinone. Kinetic and Mechanistic Aspects. Research on Chemical Intermediates, 18, 183-202. http://dx.doi.org/10.1163/156856792X00281

[12] Kobayashi, D., Honma, C., Matsumoto, H., Takahashi, T., Shimada, Y., Kuroda, C., Otake, K. and Shono, A. (2014) Effect of Ultrasonic Frequency and Initial Concentration on Degradation of Methylene Blue. Japanese Journal of Applied Physics, 53, 07KE03. http://dx.doi.org/10.7567/jjap.53.07ke03

[13] Kobayashi, D., Honma, C., Matsumoto, H., Takahashi, T., Kuroda, C., Otake, K. and Shono, A. (2014) Kinetics Analysis for Development of a Rate Constant Estimation Model for Ultrasonic Degradation Reaction of Methylene Blue. Ultrasonics Sonochemistry, 21, 1489-1495. http://dx.doi.org/10.1016/j.ultsonch.2013.12.022

[14] Kobayashi, D., Honma, C., Suzuki, A., Takahashi, T., Matsumoto, H., Kuroda, C., Otake, K. and Shono, A. (2012) Comparison of Ultrasonic Degradation Rates Constants of Methylene Blue at $22.8 \mathrm{kHz}, 127 \mathrm{kHz}$, and $490 \mathrm{kHz}$. Ultrasonics Sonochemistry, 19, 745-749. http://dx.doi.org/10.1016/j.ultsonch.2012.01.004

[15] Son, Y., Cho, E., Lim, M. and Khim, J. (2010) Effects of Salt and pH on Sonophotocatalytic Degradation of Azo Dye Reactive Black 5. Japanese Journal of Applied Physics, 49, 07HE05. http://dx.doi.org/10.1143/jjap.49.07he05

[16] Merouani, S. Hamdaoui, O., Saoudi, F. and Chiha, M. (2010) Sonochemical Degradation of Rhodamine B in Aqueous Phase: Effects of Additives. Chemical Engineering Journal, 158, 550-557. http://dx.doi.org/10.1016/j.cej.2010.01.048

[17] Inoue, M., Okada, F., Sakurai, A. and Sakakibara, M. (2006) A New Development of Dyestuffs Degradation System Using Ultrasound. Ultrasonics Sonochemistry, 13, 313-320. http://dx.doi.org/10.1016/j.ultsonch.2005.05.003

[18] Okitsu, K., Iwasaki, K., Yobiko, Y., Bandow, H., Nishimura, R. and Maeda, Y. (2005) Sonochemical Degradation of Azo Dyes in Aqueous Solution: ANew Heterogeneous Kinetics Model Taking into Account the Local Concentration of OH Radicals and Azo Dyes, Ultrasonics Sonochemistry, 12, 255-262. http://dx.doi.org/10.1016/j.ultsonch.2004.01.038

[19] Kubo, M., Matsuoka, K., Takahashi, A., Shibasaki-Kitakawa, N. and Yonemoto, T. (2005) Kinetics of Ultrasonic Degradation of Phenol in the Presence of $\mathrm{TiO}_{2}$ Particles. Ultrasonics Sonochemistry, 12, 263-269. http://dx.doi.org/10.1016/j.ultsonch.2004.01.039

[20] Sekiguchi, H. and Saita, Y. (2001) Effect of Alumina Particles on Sonolysis Degradation of Chlorobenzene in Aqueous Solution. Journal of Chemical Engineering of Japan, 34, 1045-1048. http://dx.doi.org/10.1252/jcej.34.1045

[21] Honma, C., Kobayashi, D., Matsumoto, H., Takahashi, T., Kuroda, C., Otake, K. and Shono, A. (2013) Effect of Particle Addition on Degradation Rate of Methylene Blue in an Ultrasonic Field. Japanese Journal of Applied Physics, 52, 07HE11. http://dx.doi.org/10.7567/jjap.52.07he11

[22] Contamine, R.F., Wilhelm, A.M., Berlan, J. and Delmas, H. (1995) Power Measurement in Sonochemistry. Ultrasonics Sonochemistry, 2, S43-S47. http://dx.doi.org/10.1016/1350-4177(94)00010-p

[23] Lee, B.-N., Liaw, W.-D. and Lou, J.-C. (1999) Photocatalytic Decolorization of Methylene Blue in Aqueous $\mathrm{TiO}_{2}$ Suspension. Environmental Engineering Science, 16, 165-175. http://dx.doi.org/10.1089/ees.1999.16.165 